\title{
Effects of a triazole fungicide and a pyrethroid insecticide on the decomposition of leaves in the presence or absence of macroinvertebrate shredders
}

\author{
Jes Jessen Rasmussen ${ }^{\mathrm{a}, *}$, Rikke Juul Monberg ${ }^{\mathrm{a}, \mathrm{b}}$, Annette Baattrup-Pedersen ${ }^{\mathrm{a}}$, Nina Cedergreen ${ }^{\mathrm{c}}$, \\ Peter Wiberg-Larsen ${ }^{\mathrm{a}}$, Bjarne Strobel ${ }^{\mathrm{c}}$, Brian Kronvang ${ }^{\mathrm{a}}$ \\ a Aarhus University, Department of Bioscience, Vejlsøvej 25, 8600 Silkeborg, Denmark \\ b Department for Forest and Landscape, University of Copenhagen, Rolighedsvej 23, 1958 Frederiksberg C, Denmark

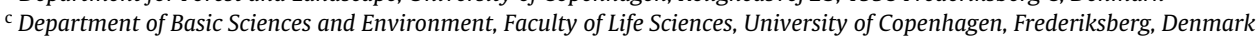

\section{A R T I C L E I N F O}

\section{Article history:}

Received 21 February 2012

Received in revised form 23 March 2012

Accepted 27 March 2012

\section{Keywords:}

Leaf litter decomposition

Pesticides

Macroinvertebrates

Microorganisms

Mixture

Pulse exposure

\begin{abstract}
A B S T R A C T
Previously, laboratory experiments have revealed that freely diluted azole fungicides potentiate the direct toxic effect of pyrethroid insecticides on Daphnia magna. More ecologically relevant exposure scenarios where pesticides are adsorbed have not been addressed. In this study we exposed beech leaves (Fagus sylvatica) to the azole fungicide propiconazole ( 50 or $500 \mu \mathrm{g} \mathrm{L}^{-1}$ ), the pyrethroid insecticide alphacypermethrin $\left(0.1\right.$ or $\left.1 \mu \mathrm{g} \mathrm{L}^{-1}\right)$ or any combination of the two for $3 \mathrm{~h}$. Exposed leaves were transferred to aquaria with or without an assemblage of macroinvertebrate shredders, and we studied treatment effects on rates of microbial leaf decomposition, microbial biomass (using C:N ratio as a surrogate measure) and macroinvertebrate shredding activity during 26 days post-exposure. Microbial leaf decomposition rates were significantly reduced in the propiconazole treatments, and the reduction in microbial activity was significantly correlated with loss of microbial biomass (increased C:N ratio). Macroinvertebrate shredding activity was significantly reduced in the alpha-cypermethrin treatments. In addition, the macroinvertebrate assemblage responded to the propiconazole treatments by increasing their consumption of leaf litter with lower microbial biomass, probably to compensate for the reduced nutritional quality of this leaf litter. We found no interaction between the two pesticides on macroinvertebrate shredding activity, using Independent Action as a reference model. In terms of microbial leaf decomposition rates, however, alpha-cypermethrin acted as an antagonist on propiconazole. Based on these results we emphasise the importance of considering indirect effects of pesticides in the risk assessment of surface water ecosystems.
\end{abstract}

(c) 2012 Elsevier B.V. All rights reserved.

\section{Introduction}

The conversion of coarse particulate organic matter (CPOM) into fine particulate organic matter (FPOM) is a fundamental stream ecosystem process that is primarily mediated by microorganisms and shredding macroinvertebrates. Microorganisms, especially hyphomycetes, are important for the conversion of leaf litter into more palatable food resources for macroinvertebrate shredders and collectors/gatherers as they degrade indigestible polysaccharides and increase the nutritional value of leaves (Bärlocher and Kendrick, 1975b; Gessner et al., 2007). Shredding macroinvertebrates convert СРОM into minor leaf fragments and faecal pellets (Graca, 2001), and several species of macroinvertebrates have been shown to consistently select or reject leaf fragments dependent on the species of aquatic fungi that colonised the leaf material (Arsuffi

\footnotetext{
* Corresponding author. Tel.: +45 87158779

E-mail address: jr@dmu.dk (J.J. Rasmussen).
}

and Suberkropp, 1989). However, total microbial biomass on leaves is recognised as an overall robust indicator for preferred macroinvertebrate shredding activity (Graca, 2001; Gulis et al., 2006).

Periodic contamination with agricultural pesticides potentially impairs the structure and/or the function of stream biota, and agricultural streams are recognised as some of the most impacted on earth (MEA, 2005). Indeed, the co-occurrence of numerous pesticides in agricultural streams has been reported frequently in scientific studies and monitoring programs (Bøgestrand, 2007; Martin et al., 2003; Rasmussen et al., 2011; Schäfer et al., 2011b).

Research reviews of the interaction between chemical toxicants in mixtures show that the vast majority of effects can be predicted with the model of concentration addition (Belden et al., 2007; Cedergreen et al., 2008; Deneer, 2000). However, in approximately $5 \%$ of the studies of binary mixtures the effect was significantly potentiated, and the majority of these studies involved azole fungicides (Cedergreen et al., 2006, 2008; Nørgaard and Cedergreen, 2010). Azole fungicides (including triazoles and imidazoles) are $\mathrm{C} 14 \alpha$-demethylase inhibitors that obstruct the 
biosynthesis of ergosterol (a significant part of fungi cell walls) by inhibiting the activity of an enzyme belonging to the group of P450 monooxygenases (Copping and Hewitt, 1998). Their synergising potential is hypothesised to be due to inhibition of P450 monooxygenases responsible for the oxygenation and thereby degradation of other xenobiotics in target organisms (Walker, 2009). Azole fungicides are often applied to agricultural fields in tank mixtures with pyrethroid insecticides, and recent studies have confirmed that some azole fungicides synergise the effect of pyrethroid insecticides both under laboratory and field conditions (Bjergager et al., 2011; Nørgaard and Cedergreen, 2010). Field screenings of stream water have disclosed concentrations up to $175 \mu \mathrm{g} \mathrm{L}^{-1}$ and $6.2 \mu \mathrm{g} \mathrm{L}^{-1}$ of azole fungicides and pyrethroid insecticides, respectively (Elsaesser and Schulz, 2008; Liess et al., 1999). However, due to their physicochemical properties pyrethroids and some azole fungicides probably primarily occur in surface waters as sorptioncomplexes with organic particles (Ding et al., 2010; Ensminger et al., 2011).

Short term effects of pyrethroid insecticides on benthic macroinvertebrates have been reported to include reduced feeding rate of some shredders and grazers (Lauridsen et al., 2006; Rasmussen et al., 2008) and altered locomotor behaviour (Nørum et al., 2010), whereas long term effects include reduced growth, fecundity and emergence success (Liess and Schulz, 1996; Schulz and Liess, 2001a,b). Recently, research on effects of fungicides on non-target microorganisms has received increasing attention, and changes in structure or function of microbial communities have been documented in laboratory studies and in the field (Dijksterhuis et al., 2011; Rasmussen et al., 2012; Schäfer et al., 2011a). Moreover, Bundschuh et al. (2011) showed that Gammarus fossarum preferred unexposed leaves over those that were previously exposed to an azole fungicide, and this selective behaviour was ascribed to pesticide-induced changes in the microbial community structure associated with the leaf fragments. In the field, however, these effects may be counteracted by functional redundancy and high abundances of shredders such as Gammaridae (Piscart et al., 2009; Rasmussen et al., 2012). Moreover, in agricultural streams shredding macroinvertebrates may not have the option to select between exposed and unexposed sources of food.

In the present study we applied a classic cross-factorial design to study the decomposition rates of leaf litter that was pulse-exposed to the triazole fungicide propiconazole and/or the pyrethroid insecticide alpha-cypermethrin. The decomposition rates were studied in the presence or absence of an assemblage of macroinvertebrate shredders. In addition, we used the $\mathrm{C}: \mathrm{N}$ ratio of leaves as a proxy for microbial biomass and nutritional quality for macroinvertebrate shredders (as C: $\mathrm{N}$ ratio decreases with increasing biomass of fungi). More specifically we tested the hypotheses that (1) propiconazole exposure reduces the biomass of leaf-associated fungi (increasing the $\mathrm{C}: \mathrm{N}$ ratio) which is additionally reflected by reduced rates of microbial leaf decomposition, (2) alpha-cypermethrin exposure decreases the rate of macroinvertebrate shredding due to either direct toxic effects or a repelling effect, (3) the toxicity of alphacypermethrin to macroinvertebrates is potentiated by the presence of propiconazole, and (4) the average macroinvertebrate shredding activity will increase with decreased nutritional quality of leaves (higher $\mathrm{C}: \mathrm{N}$ ratio), as the shredding macroinvertebrates must compensate for low nutritional quality of ingested food by increasing the feeding rate in order to maintain basic body functions. This picture may, however, be obscured by the direct toxic effect of alpha-cypermethrin on macroinvertebrates in the insecticide and combination treatments. The joint effects of alpha-cypermethrin and propiconazole were predicted using the model of independent action (IA) (Bliss, 1939). This model was chosen as the two pesticides are expected to have different modes of action on the two measured endpoints, microbial and shredder mediated leaf
Table 1

Chemical parameters for stream water used in the laboratory experiment.

\begin{tabular}{ll}
\hline Chemical parameters & Concentration $\left(\mathrm{mg} \mathrm{L}^{-1}\right)$ \\
\hline $\mathrm{NH}_{4}-\mathrm{N}$ & 0.006 \\
$\left(\mathrm{NO}_{2}+\mathrm{NO}_{3}\right)-\mathrm{N}$ & 2.57 \\
Total N & 2.79 \\
$\mathrm{PO}_{4}-\mathrm{P}$ & 0.002 \\
Total P & 0.003 \\
Total Fe & 0.004 \\
$\mathrm{pH}$ & 7.0 \\
\hline
\end{tabular}

decomposition, with propiconazole having a direct fungicidal effect on the fungal community colonising the leaves, while alphacypermethrin will most likely only exhibit a narcotic toxicity towards microorganisms which lack the nervous system of higher organisms. The shredders are, however, likely to be directly affected by alpha-cypermethrin through its effect on the nervous system (Copping and Hewitt, 1998), whereas propiconazole should not have a direct toxic effect apart from the mentioned potential effects on the P450 mediated metabolism of the macroinvertebrates (Walker, 2009).

\section{Materials and methods}

\subsection{Leaf packs}

Beech leaves (Fagus sylvatica) were collected in April, 2009 from Søndervinge Brook - an unpolluted first order stream in a catchment that is dominated by old beech forest. Thus, the collected leaves were supposed to be uncontaminated by pesticides prior to the experiment and were further assumed to be colonised with microorganisms. The leaves were stored in lightly aerated stream water at $10^{\circ} \mathrm{C}$ for three weeks prior to the experiment to allow for the microorganism community to adapt to laboratory conditions using a diurnal light/darkness cycle of $14 \mathrm{~h} / 10 \mathrm{~h}$, respectively. Water chemistry of the stream water used at all stages of the experiment is presented in Table 1.

Leaves used in the experiment were carefully selected with highest possible similarity in terms of texture and colour. Based on 50 randomly selected leaves the relation between fresh weight (FW) and dry weight (DW) for the leaves was established prior to the experiment. The leaves were blotted and the petiole was removed from all leaves before establishing the relationship between FW and DW. The DW was obtained by drying the leaves to constant mass at $60^{\circ} \mathrm{C}$. The leaves were subsequently weighed using a Mettler Toledo XP-204 (10 $\mu$ g accuracy).

Leaf packs for the experiment were produced the day before exposure by stacking 4-6 leaf discs $(2 \mathrm{~cm}$ diameter, petioles removed if present) with a total weight of $0.30 \pm 0.01 \mathrm{~g}$ FW. The introduced leaf packs function as substrate for microbial organisms and as food source for macroinvertebrate shredders. The leaf discs were threaded in a bundle using a polyester string.

\subsection{Macroinvertebrates}

The macroinvertebrates that were used in this study included two species: the amphipod Gammarus pulex (L.) and the caddisfly Halesus radiatus (Curtis). They were collected in early May 2009, in uncontaminated streams (Hagenstrup Millbrook, eastern Jutland, for G. pulex and Silke Stream, South Funen, for H. radiatus). All macroinvertebrates were stored in lightly aerated stream water at $10^{\circ} \mathrm{C}$ with sufficient leaf material to avoid biased rates of leaf decomposition in the early phase of the experiment due to starved individuals. To harmonise the size of animals for the study, G. pulex smaller than $10 \mathrm{~mm}$ in length were discarded, whereas only instars IV and V of $H$. radiatus were selected. However, in order to relate 
the size of animals to results from previous studies, we calculated the average DW of G. pulex based on a previously published relation between the length of the first thoracic segment and their DW $(n=50)$ (Iversen and Jessen, 1977). The DW of the incubated $H$. radiatus was measured as the average DW $(n=50)$ drying the animals to constant mass at $60^{\circ} \mathrm{C}$. The average DW was $4.37 \pm 0.14 \mathrm{mg}$ for $G$. pulex and $4.56 \pm 0.10 \mathrm{~g}$ for $H$. radiatus.

\subsection{Pesticides and exposure}

Propiconazole and alpha-cypermethrin were applied as the analytical standards PESTANAL ${ }^{\circledR}(99.8 \%$ purity) and were purchased from Sigma-Aldrich (Selze, Germany). Dilutions of the pesticides were produced immediately before use using a dilution series based on $96 \%$ ethanol. The stock solutions were additionally produced in $96 \%$ ethanol. Nominal exposure concentrations were $50 \mu \mathrm{g} \mathrm{L}^{-1}$ and $500 \mu \mathrm{g} \mathrm{L}^{-1}$ for propiconazole and $0.1 \mu \mathrm{g} \mathrm{L}^{-1}$ and $1 \mu \mathrm{g} \mathrm{L}^{-1}$ for alphacypermethrin including all combinations of propiconazole and alpha-cypermethrin. All pesticide exposure concentration were applied in $5 \mathrm{ml}$ 96\% ethanol, and control aquaria received an equivalent concentration of ethanol in order to compensate for potentially unintended effects of ethanol.

The leaves were exposed to pesticides in $2 \mathrm{~L}$ glass tanks in lightly aerated and moderately stirred stream water at $10^{\circ} \mathrm{C}$ for $3 \mathrm{~h}$ reflecting one runoff episode from agricultural fields (Wauchope, 1978). One water sample was collected from the exposure tank before the leaves were submerged in order to verify actual exposure concentrations. Following the pesticide exposure, the leaves were transferred to plastic aquaria with lightly aerated stream water for $24 \mathrm{~h}$ to remove potential pesticides that were not adsorbed to the leaves. Lastly, the leaf packs were transferred to the aquaria microcosms with or without the macroinvertebrates.

Actual pesticide concentrations were measured using a method that is based on solid phase extraction of propiconazole and alpha-cypermethrin followed by quantification by reverse-phase HPLC-MS. The method is described in full detail in Nørum et al. (2010), and the detection limit was $10 \mathrm{ng} \mathrm{L}^{-1}$ for both compounds. The actual concentrations of alpha-cypermethrin were $60-90 \%$ of the nominal concentration which is acceptable given the physicochemical properties of the compound. The actual concentrations of propiconazole were $80-90 \%$ of nominal concentrations. For clarity the nominal concentrations are used in the succeeding parts of the article. We attempted to measure pesticide content on leaves using acetone to extract alpha-cypermethrin and propiconazole from the leaves and subsequently analyse the extract by gas chromatography and mass spectrometry ( $\mathrm{GC}-\mathrm{MS} / \mathrm{NCI}$; $\mathrm{NCI}=$ Negative Chemical Ionisation). However, we were unable to obtain sufficiently low detection limits to measure the actual pesticide contents on leaves.

\subsection{Experimental set-up}

The study was conducted at $10^{\circ} \mathrm{C}$ using a diurnal light/dark cycle of $14 / 10 \mathrm{~h}$. Triplicate plastic aquaria (25 L) were used to study rates of leaf decomposition facilitated by microbial decomposers and/or macroinvertebrate shredders. A plastic net ( $500 \mu \mathrm{m}$ mesh size) was mounted to the smooth aquarium floor to provide a substrate suitable for the crawling of $H$. radiatus. The water was lightly aerated in all aquaria. A classic cross factorial design was used to study the rates of decomposition (with or without macroinvertebrates) of leaves that were pre-exposed to propiconazole $\left(50 \mu \mathrm{g} \mathrm{L}^{-1}\right.$ and $\left.500 \mu \mathrm{g} \mathrm{L}^{-1}\right)$, alpha-cypermethrin $\left(0.1 \mu \mathrm{g} \mathrm{L}^{-1}\right.$ and $\left.1 \mu \mathrm{g} \mathrm{L}^{-1}\right)$ or any combination of propiconazole and alpha-cypermethrin, and a control group was added (Table 2). Triplicate aquaria were applied for each treatment totally amounting to two sets of 27 aquaria (one set with and one set without macroinvertebrates). Twentyone leaf packs were designated with ID (on small plastic labels) and
Table 2

Treatments with the insecticide alpha-cypermethrin and the fungicide propiconazole in the laboratory experiment with leaf packs (with and withou macroinvertebrate shredders). Each of the nine different treatments was triplicated.

\begin{tabular}{|c|c|c|c|c|}
\hline & & \multicolumn{3}{|c|}{ Propiconazole $\left(\mu \mathrm{gL}^{-1}\right)$} \\
\hline & & 0 & 50 & 500 \\
\hline \multirow{3}{*}{$\begin{array}{l}\text { Alpha-cypermethrin } \\
\left(\mu \mathrm{gL}^{-1}\right)\end{array}$} & 0 & Control & + & + \\
\hline & 0.1 & + & + & + \\
\hline & 1.0 & + & + & + \\
\hline
\end{tabular}

transferred to each of the aquaria. The average sum weight of leaf packs was $1.38 \pm 0.01 \mathrm{~g}$ DW per aquarium. Furthermore, three $H$. radiatus and $33 \mathrm{G}$. pulex were introduced to each of 27 aquaria. The rationale behind the shredder ratio was that $G$. pulex in most streams would be significantly more abundant, but at the same time significantly less efficient in the shredding process than $H$. radiatus (Friberg, 1997; Rasmussen et al., 2012).

On experimental days 3, 6, 11, 18 and 26 three leaf packs were collected from each aquarium using the leaf pack ID to randomise the sampling. Moreover, the macroinvertebrates in each aquarium were registered as alive or dead. Sampled leaf packs were stored at $-18^{\circ} \mathrm{C}$. In order to maximise the ability to compare timeintegrated shredding activities, and to minimise temporal changes of macroinvertebrate density dependant competition for space and food among treatments, the ratio between numbers of remaining leaf packs and macroinvertebrates was maintained at a constant level by removing equal proportions of leaves and macroinvertebrates during each sampling. Removed macroinvertebrates were preserved in 96\% ethanol. At day 26 the experiment was terminated and remaining leaves and macroinvertebrates were collected and stored at $-18^{\circ} \mathrm{C}$ and in $96 \%$ ethanol, respectively.

\subsection{Leaf contents of carbon and nitrogen}

The ratio between carbon $(\mathrm{C})$ and nitrogen $(\mathrm{N})$ content in leaves was used as a proxy for microbial biomass, while also reflecting the nutritional quality of leaves for shredding macroinvertebrates (Gessner and Chauvet, 1994; Gessner et al., 2007). Total carbon and nitrogen abundances were determined according to the method described in Scrimgeour and Robinson (2003). The dried leaf packs were ground individually and $5.6 \pm 0.4 \mathrm{mg}$ of the ground leaf material from each pack were weighed into $6 \times 4 \mathrm{~mm}$ tin cups for analysis by continuous flow Dumas combustion using a Roboprep CN sample converter (Europa Scientific, Crewe, UK) in line with a Tracermass spectrometer (Europa Scientific, Crewe, UK). Samples were quantified relative to a leucine/citric acid mixture of known $\mathrm{C}$ and $\mathrm{N}$ contents.

\subsection{Data analysis}

For each aquarium the remaining dry mass of leaves was fit to the exponential decay model

$m_{\mathrm{t}}=m_{0} * e^{-\mathrm{kt}}$.

where $m_{\mathrm{t}}$ is the leaf dry mass remaining at time $t, m_{0}$ is the initial dry mass and $k\left(\right.$ day $\left.^{-1}\right)$ is the rate of leaf decomposition. The $k$ was applied as measure for leaf decomposition for microbial decomposition and macroinvertebrate shredding activity (Abelho, 2001), hence, one $k$ value was calculated for each aquarium (Appendix A).

Two-way analysis of variance was used to analyse for potential differences in rates of leaf decomposition $(k)$, macroinvertebrate mortality and average $\mathrm{C}: \mathrm{N}$ ratios among pesticide treatments $(n=3$, $P<0.05)$. The Shapiro-Wilk test was used to test for normal distribution, the Levene's test was used to test for homogeneity of variance, and Bonferoni adjusted Fisher LSD was used as post hoc 
test for pairwise differences (alpha $=0.05$ ). Moreover, we used oneway analysis of variance to analyse for potential differences in rates of leaf decomposition $(k)$ in the presence or absence of macroinvertebrate shredders among three of the pesticide treatments. We tested for differences in macroinvertebrate shredding activity among treatments with $0,0.1$ and $1 \mu \mathrm{g} \mathrm{L}{ }^{-1}$ alpha-cypermethrin within each of the propiconazole treatments $\left(0,50\right.$ and $\left.500 \mu \mathrm{g} \mathrm{L}^{-1}\right)$, and we tested for differences in microbial decomposition rates among propiconazole treatments $\left(0,50\right.$ and $\left.500 \mu \mathrm{g} \mathrm{L}^{-1}\right)$ within each of the alpha-cypermethrin treatments $\left(0,0.1\right.$ and $\left.1 \mu \mathrm{g} \mathrm{L}^{-1}\right)$. We used the Bonferoni adjusted Fisher LSD as post hoc test, and for clarity we decided a priori only to compare the C:N ratio for each treatment to the C:N ratio for the control group. Homogeneity of variance was confirmed for all data. All ANOVAs and post hoc tests were conducted using SAS Enterprise Guide 4.2.

Using linear regressions we tested strength of the correlation between rates of microbial litter decomposition and the $\mathrm{C}: \mathrm{N}$ ratio of leaves. Furthermore, we tested if the nutritional quality of leaves (C:N ratio) was a significant predictor for macroinvertebrate shredding activity. We used the $\mathrm{C}: \mathrm{N}$ ratios measured on experimental days $3,6,11,18,26$ and the time-weighed average $(n=27)$ as input parameters. All regression analyses were performed in SigmaPlot 11.0.

Possible interactions between the two pesticides on microbial decomposition and shredder activity were tested using the reference model; Independent Action (IA) (Bliss, 1939). Independent action is originally based on probabilities and states that the probability of being un-affected by a combination of chemicals is equal to the product of probabilities of not being affected by each of the chemicals separately. Expressed mathematically, this is:

$R_{\text {mix }}=R_{A} * R_{B} * \ldots R_{n}=\prod_{i=1}^{n} R_{n}$

where $R_{\text {mix }}$ is the probability of not being affected by the mixture and $R_{A}, R_{B}$, and $R_{n}$ denote the probability of not being affected by chemical $A$ or $B$ up to $n$ chemicals. Even though IA is based on the assumption of binomial endpoints and probabilities, it has been shown to be a strong descriptor of joint effects on gradual data, and often being quite similar to predictions using Concentration Addition (CA) as the reference model (Cedergreen et al., 2008). In this study, average microbial and shredder leaf decomposition rates of all mixture treatments calculated as a proportion of the untreated controls were used to calculate the IA predictions.

\section{Results}

\subsection{Microbial leaf decomposition}

We found that the rates of microbial leaf decomposition $\left(k_{\text {microbial }}\right)$ were significantly different among treatments $(P=0.003)$ with the effect of propiconazole being significant $(P<0.001)$ (Two-way ANOVA) (raw data shown in Appendix B). We found no significant effects of alpha-cypermethrin, and there were no significant interactions on $k_{\text {microbial }}(P=0.057$ and $P=0.159$, respectively). The pure $50 \mu \mathrm{gL}^{-1}$ and $500 \mu \mathrm{gL}^{-1}$ propiconazole treatments significantly reduced $k_{\text {microbial }}$ when compared to controls $\left(P=0.016\right.$ and $P=0.002$, respectively). The $k_{\text {microbial }}$ was not significantly different between the $50 \mu \mathrm{g} \mathrm{L}^{-1}$ and $500 \mu \mathrm{g} \mathrm{L}^{-1}$ propiconazole treatments $(P=0.093)$ (Fig. 1$)$. Moreover, the additional presence of alpha-cypermethrin reduced the effect of propiconazole on $k_{\text {microbial }}$, but there was still a tendency of a decreased $k_{\text {microbial }}$, but the decrease was less and not significant (Fig. 1B and C). Comparing the observed decomposition rates of the mixed treatments with the IA predictions showed that the IA predictions were lower than the observed decomposition rates and not included in

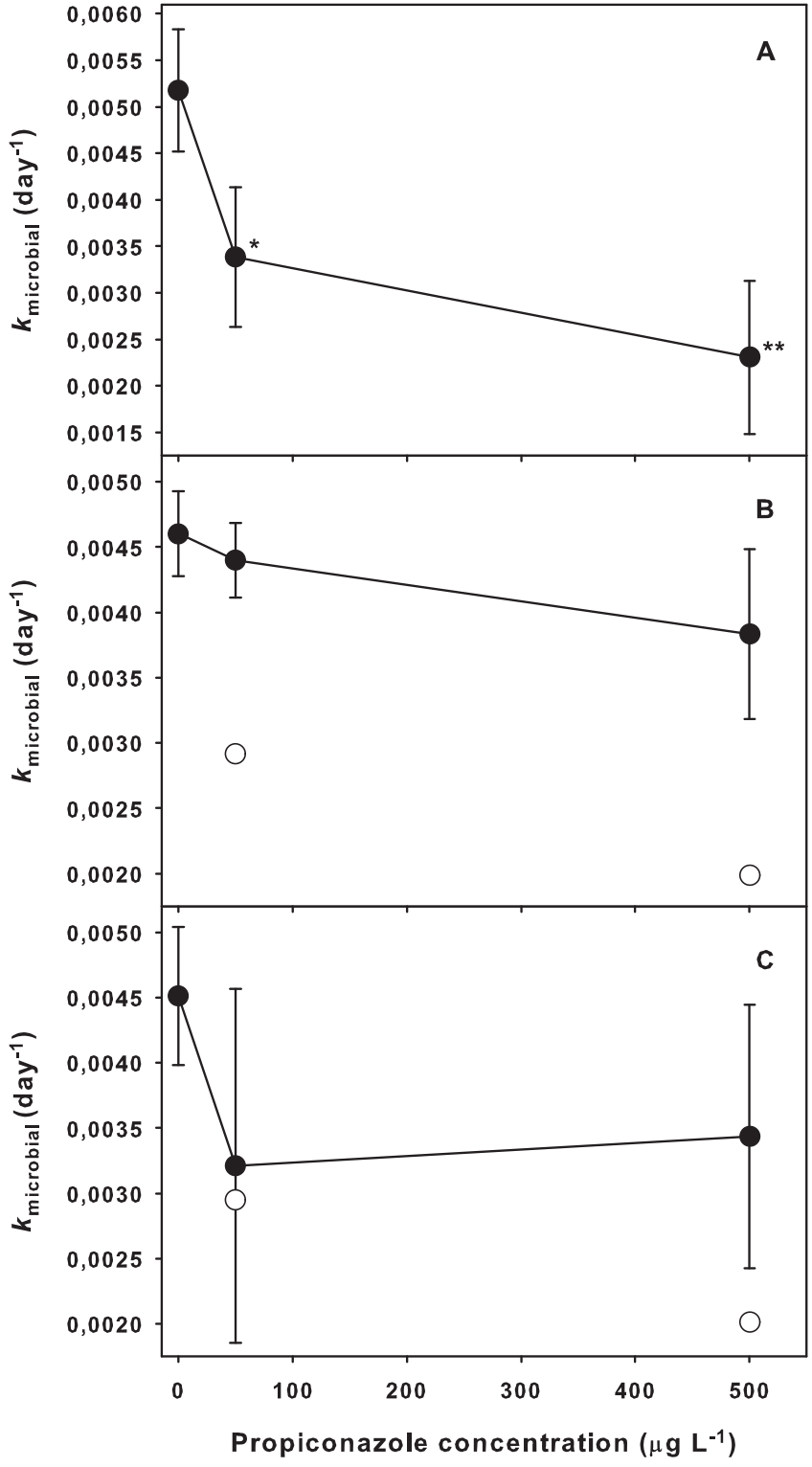

Fig. 1. Rates of leaf decomposition facilitated by microbial organisms ( $\left.k_{\text {microbial }}\right)$ subsequent to a $3 \mathrm{~h}$ pulse exposure to 0,50 or $500 \mu \mathrm{g} \mathrm{L}^{-1}$ propiconazole. Each of the propiconazole treatments were combined with the simultaneous exposure to 0 (A), 0.1 (B) or 1 (C) $\mu \mathrm{g} \mathrm{L}^{-1}$ alpha-cypermethrin. Significant effects of the treatment were found for the pure propiconazole treatments (ANOVA $P<0.05, n=3$ ). Asterisks indicate the level of significance ( ${ }^{*}$ indicates $P<0.05$ and ${ }^{* *}$ indicates $P<0.005$ ). IA predictions of the mixture treatments based on the single chemical responses are given as open symbols. Error bars indicate $95 \%$ confidence intervals.

the $95 \%$ confidence intervals in three of the four mixtures. This strongly indicates significant antagony between the two chemicals on microbial decomposition of leaves.

\subsection{Macroinvertebrate shredding activity}

We found no significant effect of pesticide treatments on macroinvertebrate mortality $(P>0.05)$ (Appendix $C)$. The macroinvertebrate shredding activity $\left(k_{\text {shredders }}\right)$ was significantly different among treatments $(P=0.047)$, and there was a significant effect of alpha-cypermethrin $(P=0.003)$, but not of propiconazole $(P=0.581)$. We found no interactions between treatments $(P=0.619)$ (Two-way ANOVA) (raw data shown in Appendix B). The pure alpha-cypermethrin treatments $\left(0.1 \mu \mathrm{g} \mathrm{L}^{-1}\right.$ and $\left.1 \mu \mathrm{g} \mathrm{L}^{-1}\right)$ significantly reduced the shredding activity compared to the 


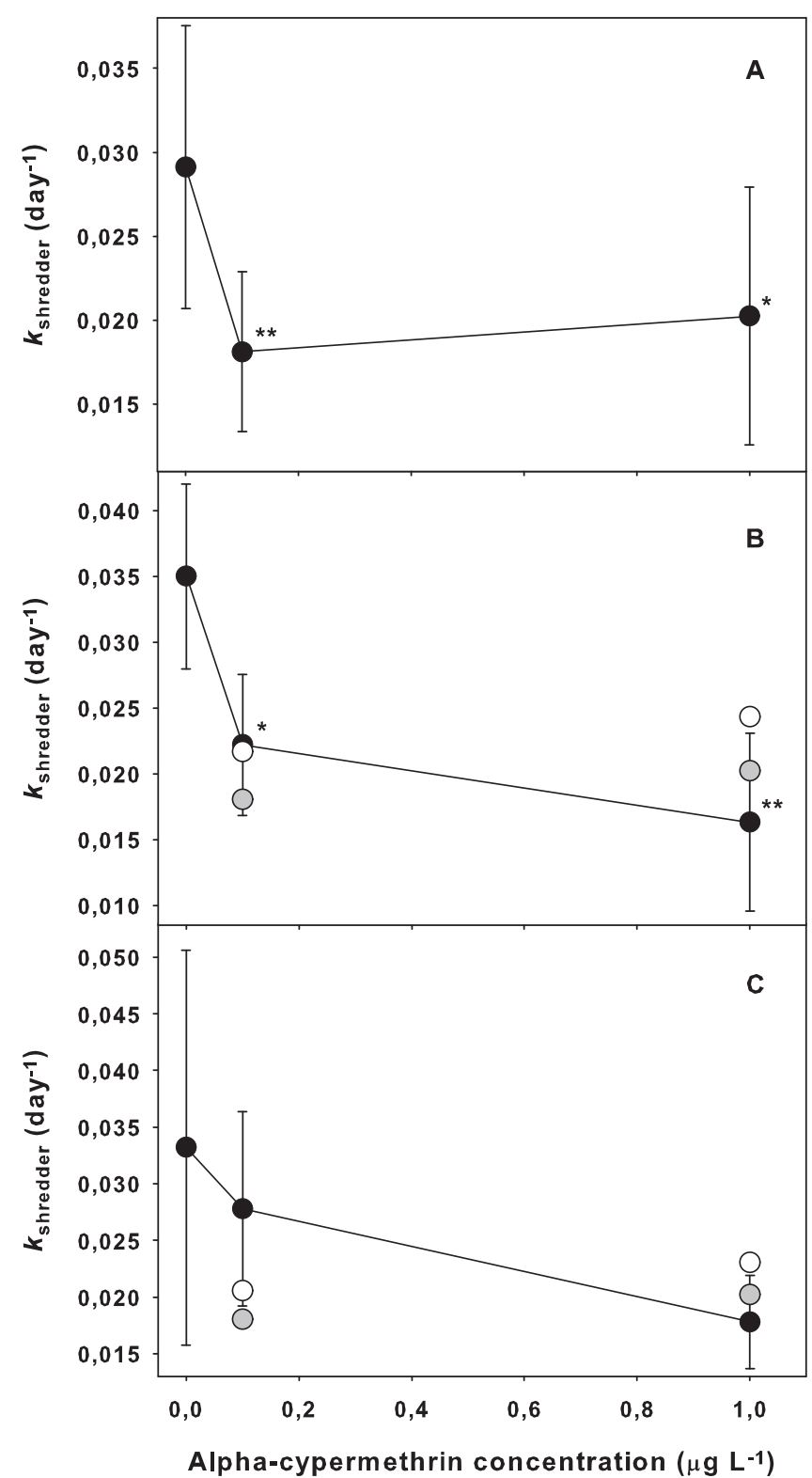

Fig. 2. Rates of leaf decomposition facilitated by macroinvertebrate shredders ( $k_{\text {shredder }}$ ). Leaves were exposed to $0,0.1$ or $1 \mu \mathrm{g} \mathrm{L}^{-1}$ alphacypermethrin for $3 \mathrm{~h}$, and after a rinsing procedure they were introduced to the macroinvertebrate shredder assemblage. Each of the alpha-cypermethrin treatments were combined with the simultaneous exposure to 0 (A), 50 (B) or 500 (C) $\mu \mathrm{g} \mathrm{L}^{-1}$ propiconazole. Significant effects of the treatment are indicated with asterisks ( ${ }^{*}$ indicates $P<0.05$ and ** indicates $P<0.005$ ). IA predictions of the mixture treatments based on the single chemical responses accepting propiconazole induced shredder stimulation are given as open symbols, while predictions not accepting stimulation are given in grey symbols. Error bars indicate $95 \%$ confidence intervals.

control ( $P=0.036$ and $P=0.003$, respectively) (Fig. $2 A)$, but there was no significant difference in shredding activity between the two alpha-cypermethrin treatments $(P=0.430)$. Additionally, the alpha-cypermethrin treatments significantly reduced the macroinvertebrates shredding activity in mixtures with $50 \mu \mathrm{g} \mathrm{L}^{-1}$ propiconazole but not in mixtures with $500 \mu \mathrm{g} \mathrm{L}^{-1}$ propiconazole $(P=0.018$ and $P=0.246$, respectively) (Fig. $2 \mathrm{~B}$ and C). As shredder rates actually increased in response to propiconazole (probably resulting from the effect of propiconazole on the nutritional quality of leaves as discussed below), this caused effect estimates to be $>1$. As IA theory is based on binary endpoints, effects above $100 \%$

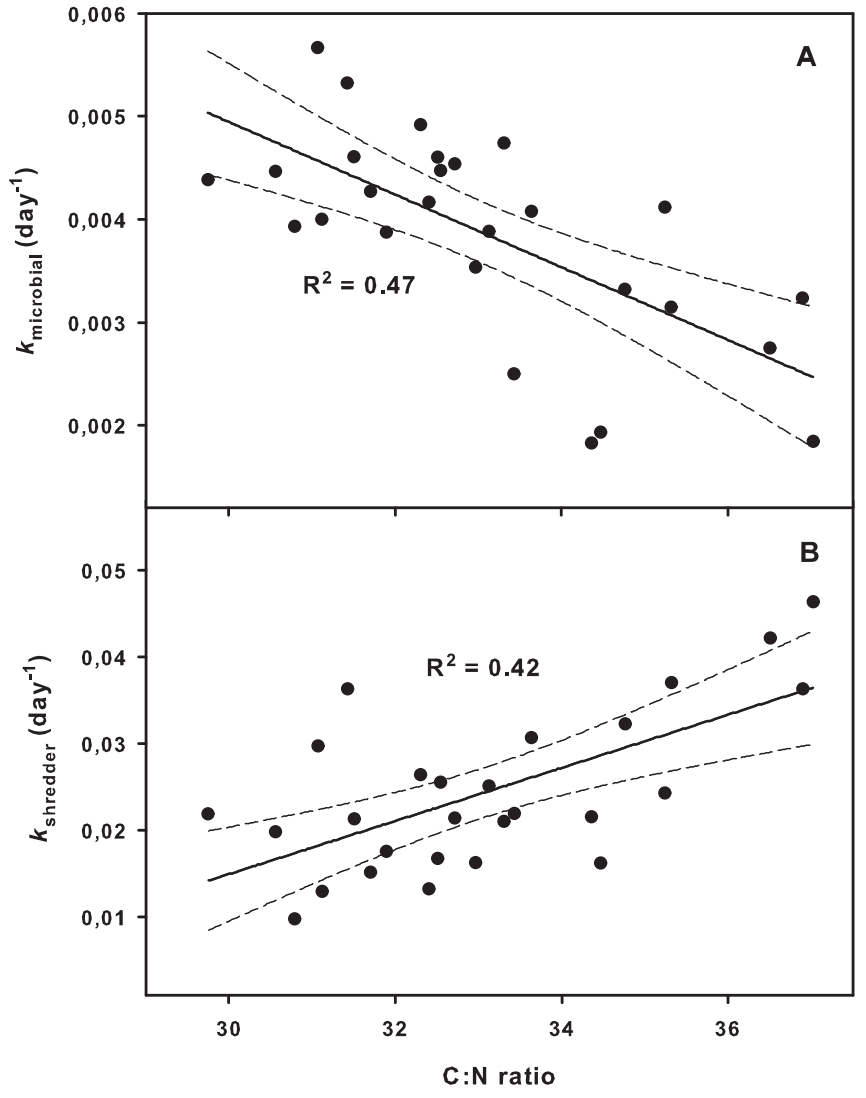

Fig. 3. The rate of leaf decomposition ( $k$ ) facilitated by microbial organisms (A) and an assemblage of macroinvertebrate shredders (B) as a function of the average C: $N$ ratio of leaves that were previously exposed to one of eight different treatments with propiconazole, alpha-cypermethrin or the combination of the two (and control). Dashed lines represent 95\% confidence intervals.

are not possible. From a biological point of view, it does, however, make sense to consider one chemical as having stimulating effects and another having inhibitory effects, with the combined effects being a product of the two (discussed in Ohlsson et al. 2010). Using the true effects of propiconazole on shredder activity (values $>1$ ) the mixed treatments with the IA predictions showed that the predictions were within the $95 \%$ confidence intervals of the observed shredding rates for both combinations of leaves treated with $0.1 \mu \mathrm{g} \mathrm{L}^{-1}$ alpha-cypermethrin. However, for the combination treatments with $1 \mu \mathrm{gL}^{-1}$ alpha-cypermethrin and 50 or $500 \mu \mathrm{g} \mathrm{L}^{-1}$ propiconazole the observed shredding rates were significantly lower than those predicted by IA (Fig. 2B and C). If the propiconazole treatment increased the shredding rates, the alphacypermethrin treatment decreased shredding rates proportionally or more than expected by IA. Assuming that the propiconazole treatment did not affect the shredding rates, IA predictions were within the $95 \%$ confidence limits for all mixture treatments (Fig. 2B and $\mathrm{C}$ ).

\subsection{C:N ratio}

We found no significant differences among the average $\mathrm{C}: \mathrm{N}$ ratios for the treatments $(P>0.05)$ (Appendix D). Moreover, we found no significant effect of pesticides on the $C: N$ ratios for experimental days $3,6,11,18$ or $26(P>0.05$, data not shown $)$. The $k_{\text {microbial }}$ significantly decreased with increasing average $C: N$ ratio for leaves $\left(R^{2}=0.47, P<0.001, n=27\right)$ (Fig. 3$)$. The slope of the regression line was significantly different from zero $(P<0.05)$. In addition, the $k_{\text {shredder }}$ significantly increased with increasing C: $N$ ratio for leaves $\left(R^{2}=0.4, P<0.001, n=27\right)$ (Fig. 3 ), and the slope of the regression 
line was significantly different from zero $(P<0.05)$. Using the $\mathrm{C}: \mathrm{N}$ ratio for experimental days $3,6,11,18$ or 26 as alternative to the average $\mathrm{C}: \mathrm{N}$ ratio for the entire study period did not improve the level of significance for any of the correlations.

\section{Discussion}

\subsection{Microbial leaf decomposition}

As hypothesised, a short pulse of the triazole fungicide propiconazole significantly reduced the rate of microbial leaf decomposition over a 26 days period, and this effect tended to increase with increasing exposure concentration. The results probably reflect a direct toxic effect of propiconazole on the fungal microbial community caused by the inhibition of $\mathrm{C} 14 \alpha-$ demethylase which is involved in the biosynthesis of ergosterol, an essential membrane sterol for fungi (Copping and Hewitt, 1998). Propiconazole is likely to adsorb to the leaf surfaces due to its lipophilic properties $\left(\log K_{\mathrm{ow}}=3.7\right)$. Since the leaf surface is colonised with microbial organisms such as freshwater fungi (Bärlocher and Kendrick, 1975a,b) the probability of propiconazole reaching the non-target freshwater fungi is expected to be relatively high, enforcing the toxic potential of propiconazole.

We did not find a significant effect of pesticide treatments on the $\mathrm{C}: \mathrm{N}$ ratio for the leaves due to large variations within treatments, but the significant decrease of microbial decomposition rates with increasing average $\mathrm{C}: \mathrm{N}$ ratio of the leaves confirms that the changes in C: $\mathrm{N}$ ratio are linked to the degree of microbial colonisation of the leaves. This indicates that the rate of microbial activity was a more sensitive endpoint than the microbial biomass estimate measured as $\mathrm{C}: \mathrm{N}$ ratio due to lower data variability. However, this rank ordering of endpoint sensitivity receives varying support in the literature (Duarte et al., 2008a; Fernandes et al., 2009; Gessner and Chauvet, 2002; Schäfer et al., 2011a). The C:N measurements reflect the sum of living and dead biomass, whereas microbial activity represents living cells only, and a slow decomposition of dead microbial organisms may be the reason for the microbial activity being the more sensitive endpoint for fungicidal effects of propiconazole in our study.

The presence of alpha-cypermethrin seemed to reduce the toxic effect of propiconazole on rates of microbial decomposition, and when compared to IA mixture toxicity predictions, alpha-cypermethrin showed antagonistic behaviour in the combination treatments. We have found no obvious explanation for this observation but can only speculate that the presence of alpha-cypermethrin may alter the sorption characteristics for propiconazole, though this seems unlikely considering the low concentrations of alpha-cypermethrin compared to propiconazole and the lipophilic binding mechanisms of both compounds. However, the attempted measurements of pesticide contents of the leaf material were not successful; hence we cannot confirm nor reject this hypothesis.

\subsection{Macroinvertebrate shredding activity}

The macroinvertebrate shredding activity was reduced by $50 \%$ compared with the control group when leaves were previously exposed to the pyrethroid insecticide alpha-cypermethrin $(0.1$ or $1 \mu \mathrm{g} \mathrm{L}^{-1}$ ). Up to $98 \%$ of molecules of this substance are (due to its high $K_{\text {ow }}$ of 6.9) proposed to form irreversible sorption complexes with organic material within $2 \mathrm{~h}$ after the introduction to freshwater (Lauridsen et al., 2006). Our results therefore most likely reflect that the macroinvertebrate shredders to some extent ceased to consume the contaminated leaves due to a direct but sublethal toxic effect of the contaminated leaves or a repelling effect. Similar effects were observed in a study of Lauridsen et al. (2006) where shredding rates of the caddis fly Sericostoma personatum were reduced when leaves were previously exposed to $0.3 \mu \mathrm{g} \mathrm{L}^{-1}$ of the pyrethroid lambda-cyhalothrin for $24 \mathrm{~h}$. In our study, the presence of two different species of macroinvertebrate shredders could possibly introduce some functional redundancy to the system, but reduced shredding activity was observed down to $0.1 \mu \mathrm{g} \mathrm{L}^{-1}$ which is clearly below the lowest concentration of observed effects in Lauridsen et al. (2006). The increased sensitivity to alpha-cypermethrin for one or both macroinvertebrate species therefore could be a potential side effect of several organisms potentially competing for food and space. Interspecies competition has been shown to significantly increase the effects of pesticide exposure in other studies (Beketov and Liess, 2005).

Propiconazole had no significant adverse effect on the macroinvertebrate shredding activity. On the contrary, shredder activity seemed to increase with increasing propiconazole exposure. Since the nutritional quality of microbial cells is 4-10 times higher than the nutritional quality of unconditioned leaves, a reduction of the microbial biomass, resulting from the exposure of propiconazole, is likely to reduce the nutritional quality of leaves (i.e. increased C:N ratio) (Bärlocher and Kendrick, 1975a,b). The reduced nutritional quality of propiconazole treated leaves could have caused the macroinvertebrate assemblage to compensate for a potential nutritional deficiency by increasing the consumption of leaf litter in order to meet energy requirements for basic physiological processes (Simpson and Simpson, 1990). Hence, even if propiconazole did not have a direct toxic effect on the shredders, it could affect the feeding behaviour and nutritional status of the shredders indirectly through its effect on the microbial colonisation of the leaves and thereby food quality.

The results of the mixture treatment additionally need to be interpreted in that context. If we accept that feeding activity increases in the presence of propiconazole, the high alpha-cypermethrin concentration decreases shredder activity proportionately more in the two propiconazole treatments compared to the decrease in the pure alpha-cypermethrin treatment. This could be interpreted as synergy, resulting either from initial increased feeding rates resulting in higher exposure to alphacypermethrin, or from propiconazole having a direct impact on the metabolisation of alpha-cypermethrin. The latter is believed to be the cause of synergy observed between freely diluted pyrethroid insecticides on Daphnia magna and other zooplankton in laboratory and microcosm studies (Bjergager et al., 2011; Nørgaard and Cedergreen, 2010). However, the variance in the test system is high, and the number of replicates is low. And if not accepting an increased shredding activity in the propiconazole treatments, but simply assuming them to be as the pure control, there is no difference between observed and predicted shredding activity in the mixture treatments. The interpretation of potential synergistic interactions between the pesticides when adsorbed to organic matter and when using a non-lethal endpoint such as shredding activity consequently needs more in-depth studies where exposure can be quantified over time together with the proposed physiological effects of both propiconazole and alpha-cypermethrin.

\subsection{Microbial biomass and nutritional quality}

We found no significant effect of pesticide treatment on the $\mathrm{C}: \mathrm{N}$ ratio of the leaves, but the average C: $\mathrm{N}$ ratios explained $47 \%$ of the variation in rates of microbial decomposition, where increasing $\mathrm{C}: \mathrm{N}$ ratios were characterised by decreasing rates of microbial decomposition. This clearly indicates that there was a general effect of the different pesticide treatments and that the $\mathrm{C}: \mathrm{N}$ ratio did reflect microbial abundance and activity. In addition, the correlation shows that there was no significant functional redundancy in 
these microorganism communities. Increasing abundance of more tolerant species, however, has been observed in other studies as a result of competitive release which is facilitated by decreasing abundance of more sensitive species as a result of toxic stress (Duarte et al., 2008b; Gessner and Chauvet, 2002). Consistent with our results Bundschuh et al. (2011) observed a significant reduction of the microbial biomass on leaves after 12 days exposure to $500 \mu \mathrm{g} \mathrm{L}^{-1}$ of the triazole fungicide tebuconazole. These results confirm that triazole fungicides are toxic for aquatic microorganisms, and the results from our study extend these findings into the range of environmentally realistic exposure durations.

As already mentioned, the rate of macroinvertebrate shredding activity significantly increased with decreasing nutritional quality of leaves (higher $\mathrm{C}: \mathrm{N}$ ratio) with low nutritional value of leaves primarily being associated with the fungicide treatments, while the increased shredder activity was believed to be a compensatory behaviour with the aim of optimising energy input (Simpson and Simpson, 1990). These interrelated responses have important implications for ecosystem functioning, because reduced nutritional quality of food may have cascading effects reducing the amount of energy available for growth and reproduction in higher trophic levels. The effect of decreased food quality and hereby energy resources may be further enhanced under natural conditions, as the shredding macroinvertebrates in streams that are impacted by agricultural pesticides may have increased energy demands in order to cope with toxic stress. Our results are supported by Bundschuh et al. (2011) who showed that triazole fungicides can reduce the overall microbial biomass, and Zubrod et al. (2011) showed that reduced nutritional value of leaves resulting from exposure to an azole fungicide increased the food intake by macroinvertebrate shredders but reduced their physiological fitness. Applying endpoints that are based on scope for growth assessments are important and highly ecologically relevant supplements to studies on the activity of secondary producers, as it provides useful information on the potential changes in interspecies competition and selective forces that arise in consequence of pesticide stress (Bundschuh et al., 2011; Zubrod et al., 2010, 2011).

\section{Conclusions}

In this study, we showed that a $3 \mathrm{~h}$ pulse exposure of environmentally realistic exposure concentrations and durations of propiconazole significantly reduced average rates of microbial leaf decomposition for the subsequent 26 days. Moreover, this reduction in leaf decomposition rates was associated with a reduction in nutrient concentrations of the leaves reflecting reduced microbial biomass. Exposing leaves to a $3 \mathrm{~h}$ pulse of alpha-cypermethrin significantly reduced shredding activity of an assemblage of macroinvertebrate shredders reflecting either direct toxic effects or a repellent effect. Alpha-cypermethrin was found to act as antagonist on propiconazole in terms of microbial activity whereas we did not find significant interactions between propiconazole and alphacypermethrin on shredding activity or mortality. Lastly, we found that macroinvertebrate shredding activity significantly increased with decreasing nutrient concentrations of leaves independent of the pesticide treatments. This effect we believe is a compensatory behaviour to maintain basic physiological processes. The results from this study have important implications for understanding the complexity of ecotoxicological effects of pesticides in the field where some toxic compounds may act on the habitat or food choice of an organism and other compounds may act on the organism itself, which eventually may increase the total ecotoxicological effect on the ecosystem structure and function.
In general, there is increasing evidence suggesting that indirect effects of chemical contaminants are more common than direct effects (Rohr et al., 2006) which clearly emphasises the need for exploring these effects at the field level in order to improve the risk assessment procedures. There is, however, a scarcity of observational field studies where comprehensive exposure analyses have been performed in order to link exposure to ecological effects (Beketov and Liess, 2012). Three field studies exist in which comprehensive pesticide exposure analyses have been linked to organic matter processing. Two of these studies congruently report pesticide effects on rates of organic matter processing induced by microorganisms, whereas the studies report conflicting results on macroinvertebrate shredding rates (Rasmussen et al., 2012; Schäfer et al., 2007, 2011a). Moreover, to our knowledge no field studies have been conducted that specifically focus on the indirect effects of pesticides on e.g. nutritional quality of organic matter. We therefore suggest conducting observational field studies to confirm the importance of indirect effects of pesticides on organic matter processing and macroinvertebrate shredders that has been observed in laboratory studies.

\section{Acknowledgements}

This study was financed by the Danish Research Council (grant no. 2104-07-0035) and is part of the RISKPOINT project. We wish to thank Johnny Nielsen, Uffe Mensberg and Marlene Venø Skjærbæk for laboratory assistance and Ulrik Nørum and Klaus Brodersen for useful feedback on set-up development and statistical analyses. In addition, we kindly acknowledge the positive and constructive feedback of two anonymous reviewers.

\section{Appendix A. Supplementary data}

Supplementary data associated with this article can be found, in the online version, at http://dx.doi.org/10.1016/ j.aquatox.2012.03.015.

\section{References}

Abelho, M., 2001. From litterfall to breakdown in streams: a review. The Scientific World Journal 1, 656-680.

Arsuffi, T.L., Suberkropp, K., 1989. Selective feeding by shredders on leaf-colonizing stream fungi - Comparison of macroinvertebrate taxa. Oecologia 79, 30-37.

Beketov, M.A., Liess, M., 2005. Acute contamination with esfenvalerate and food limitation: chronic effects on the mayfly, Cloeon dipterum. Environmental Toxicology and Chemistry 24, 1281-1286.

Beketov, M.A., Liess, M., 2012. Ecotoxicology and macroecology - Time for integration. Environmental Pollution 162, 247-254.

Belden, J.B., Gilliom, R.J., Martin, J.D., Ludy, M.J., 2007. Relative toxicity and occurrence patterns of pesticide mixtures in streams draining agricultural watersheds dominated by corn and soybean production. Integrated Environmental Assessment and Management 3, 90-100.

Bjergager, M.B.A., Hanson, M.L., Lissemore, L., Henriquez, N., Solomon, K.R. Cedergreen, N., 2011. Synergy in microcosms with environmentally realistic concentrations of prochloraz and esfenvalerate. Aquatic Toxicology 101, $412-422$.

Bliss, C.I., 1939. The toxicity of poisons applied jointly. The Annals of Applied Biology 26, 585-615.

Bundschuh, M., Zubrod, J.P., Kosol, S., Maltby, L., Stang, C., Duester, L., Schulz, R., 2011. Fungal composition on leaves explains pollutant-mediated indirect effects on amphipod feeding. Aquatic Toxicology 104, 32-37.

Bärlocher, F., Kendrick, B., 1975a. Assimilation efficiency of Gammarus pseudolimnaeus (Amphipoda) feeding on fungal mycelium or autumn shed leaves. Oikos 26, 55-59.

Bärlocher, F., Kendrick, B., 1975b. Leaf-conditioning by microorganisms. Oecologia 20, 359-362.

Bøgestrand, J., 2007. Stream conditions, 2006. NOVANA. In: Scientific Report from NERI No. 643 (In Danish). National Environmental Research Institute, Aarhus University, Aarhus, Denmark, 70pp.

Cedergreen, N., Christensen, A.M., Kamper, A., Kudsk, P., Mathiassen, S.K., Streibig J.C., Sorensen, H., 2008. A review of independent action compared to concentration addition as reference models for mixtures of compounds with different molecular target sites. Environmental Toxicology and Chemistry 27, 1621-1632. 
Cedergreen, N., Kamper, A., Streibig, J.C., 2006. Is prochloraz a potent synergist across aquatic species? A study on bacteria, daphnia, algae and higher plants. Aquatic Toxicology 78, 243-252.

Copping, L.G., Hewitt, H.G., 1998. Chemistry and Mode of Action of Crop Protection Agents. The Royal Society of Chemistry, Cambridge.

Deneer, J.W., 2000. Toxicity of mixtures of pesticides in aquatic systems. Pest Management Science 56, 516-520.

Dijksterhuis, J., van Doorn, T., Samson, R., Postma, J., 2011. Effects of seven fungicides on non-target aquatic fungi. Water, Air, and Soil Pollution 222, 421-425.

Ding, Y.P., Harwood, A.D., Foslund, H.M., Lydy, M.J., 2010. Distribution and toxicity of sediment-associated pesticides in urban and agricultural waterways from Illinois, USA. Environmental Toxicology and Chemistry 29, 149-157.

Duarte, S., Pascoal, C., Alves, A., Correia, A., Cassio, F., 2008a. Copper and zinc mixtures induce shifts in microbial communities and reduce leaf litter decomposition in streams. Freshwater Biology 53, 91-101.

Duarte, S., Pascoal, C., Cassio, F., 2008b. High diversity of fungi may mitigate the impact of pollution on plant litter decomposition in streams. Microbial Ecology 56, 688-695.

Elsaesser, D., Schulz, R., 2008. Mitigation of fungicide pollution in vegetated agricultural surface waters: GIS modelling and monitoring in the field. In: SETAC Europe 18th Annual Meeting, Warsaw, pp. 406-407.

Ensminger, M., Bregin, R., Spurlock, F., Goh, K.S., 2011. Pesticide concentrations in water and sediment and associated invertebrate toxicity in Del Puerto and Orestimba Creeks, California, 2007-2008. Journal of Environmental Monitoring and Assessment 175, 573-587.

Fernandes, I., Duarte, S., Cassio, F., Pascoal, C., 2009. Mixtures of zinc and phosphate affect leaf litter decomposition by aquatic fungi in streams. The Science of the Total Environment 407, 4283-4288.

Friberg, N., 1997. Benthic invertebrate communities in six Danish forest streams: impact of forest type on structure and function. Ecography 20,19-28.

Gessner, M.O., Chauvet, E., 1994. Importance of stream microfungi in controlling breakdown rates of leaf-litter. Ecology 75, 1807-1817.

Gessner, M.O., Chauvet, E., 2002. A case for using litter breakdown to assess functional stream integrity. Ecological Applications 12, 498-510.

Gessner, M.O., Gulis, V., Kuehn, K.A., Chauvet, E., Suberkropp, K., 2007. Fungal decomposers of plant litter in aquatic ecosystems. In: Kubicek, C.P.a.D.I.S. (Ed.), Environmental and Microbial Relationships. , 2nd ed. Springer Verlag, Berlin.

Graca, M.A.S., 2001. The role of invertebrates on leaf litter decomposition in streams - A review. International Review of Hydrobiology 86, 383-393.

Gulis, V., Ferreira, V., Graca, M.A.S., 2006. Stimulation of leaf litter decomposition and associated fungi and invertebrates by moderate eutrophication: implications for stream assessment. Freshwater Biology 51, 1655-1669.

Iversen, T.M., Jessen, J., 1977. Life-cycle, drift and production of Gammarus pulex L. (Amphipoda) in a Danish spring. Freshwater Biology 7, 287-296.

Lauridsen, R.B., Kronvang, B., Friberg, N., 2006. Occurrence of sediment-bound pyrethroids in danish streams and their impact on ecosystem function. Water, Air, and Soil Pollution 6, 423-432.

Liess, M., Schulz, R., 1996. Chronic effects of short-term contamination with the pyrethroid insecticide fenvalerate on the caddisfly Limnephilus lunatus. Hydrobiologia 324, 99-106.

Liess, M., Schulz, R., Liess, M.H.D., Rother, B., Kreuzig, R., 1999. Determination of insecticide contamination in agricultural headwater streams. Water Research 33, 239-247.

Martin, J.D., Crawford, C.G., Larson, S.J., 2003. Pesticides in Streams. National Water Assessment Program (NAWQA), USA.

Millenium Ecosystem Assessment, 2005. Millenium Ecosystem Assessment. Ecosystems and Human Well-being: Synthesis. Island Press, Washington, DC.

Nørgaard, K.B., Cedergreen, N., 2010. Pesticide cocktails can interact synergistically on aquatic crustaceans. Environmental Science and Pollution Research 17, 957-967.
Nørum, U., Friberg, N., Jensen, M., Pedersen, J., Bjerregaard, P., 2010. Behavioural changes in three species of freshwater macroinvertebrates exposed to the pyrethroid lambda-cyhalothrin: laboratory and stream microcosm studies. Aquatic Toxicology 98, 328-335.

Ohlsson, A., Cedergreen, N., Oskarsson, A., Ulleras, E., 2010. Mixture effects of imidazole fungicides on cortisol and aldosterone secretion in human adrenonocortical H295R cells. Toxicology 275, 21-28.

Piscart, C., Genoel, R., Doledec, S., Chauvet, E., Marmonier, P., 2009. Effects of intense agricultural practices on heterotrophic processes in streams. Environmental Pollution 157, 1011-1018.

Rasmussen, J.J., Baattrup-Pedersen, A., Wiberg-Larsen, P., McKnight, U.S., Kronvang B., 2011. Buffer strip width and agricultural pesticide contamination in Danish lowland streams: implications for stream and riparian management. Ecological Engineering 37, 1990-1997.

Rasmussen, J.J., Friberg, N., Larsen, S.E., 2008. Impact of lambda-cyhalothrin on a macroinvertebrate assemblage in outdoor experimental channels: implications for ecosystem functioning. Aquatic Toxicology 90, 228-234.

Rasmussen, J.J., Wiberg-Larsen, P., Baattrup-Pedersen, A., Monberg, R.J., Kronvang, B., 2012. Impacts of pesticides and natural stressors on leaf litter decomposition in agricultural streams. The Science of the Total Environment 416, 148-155.

Rohr, J.R., Kerby, J.L., Sih, A., 2006. Community ecology as a framework for predicting contaminant effects. Trends in Ecology \& Evolution 21, 606-613.

Schäfer, R., Caquet, T., Siimes, K., Mueller, R., Lagadic, L., Liess, M., 2007. Effects of pesticides on community structure and ecosystem functions in agricultural streams of three biogeographic regions in Europe. Science of the Total Environment 382 272-285.

Schulz, R., Liess, M., 2001a. Acute and chronic effects of particle-associated fenvalerate on stream macroinvertebrates: a runoff simulation study using outdoor microcosms. Archives of Environmental Contamination and Toxicology 40, $481-488$.

Schulz, R., Liess, M., 2001b. Toxicity of aqueous-phase and suspended particleassociated fenvalerate: chronic effects after pulse-dosed exposure of Limnephilus lunatus (Trichoptera). Environmental Toxicology and Chemistry 20, 185-190.

Schäfer, R.B., Bundschuh, M., Rouch, D.A.E.S., Von der Ohe, P.C., Pettigrove, V., Schulz, R., Nugegoda, D., Kefford, B., 2011a. Effects of pesticide toxicity, salinity and other environmental variables on selected ecosystem functions in streams and the relevance for ecosystem services. The Science of the Total Environment 415, 69-78.

Schäfer, R.B., Pettigrove, V., Rose, G., Allinson, G., Wightwick, A., von der Ohe, P.C., Shimeta, J., Kuhne, R., Kefford, B., 2011b. Effects of pesticides monitored with three sampling methods in 24 sites on macroinvertebrates and microorganisms. Environmental Science \& Technology 45, 1665-1672.

Scrimgeour, C.M., Robinson, D., 2003. Stable isotope analysis and applications. In: Smith, K.A., Cresser, M.S. (Eds.), Soil and Environmental Analysis: Modern Instrumental Techniques., 3rd ed. Marcel Dekker Inc., New York, NY, USA, pp. 381-431.

Simpson, S.J., Simpson, C.L., 1990. The mechanisms of nutritional compensation by phytophagous insects. In: Bernays, E.A. (Ed.), Insect-Plant Interactions. CRC Press, Boca Raton, Florida, USA, pp. 111-160.

Walker, C.H., 2009. Factors determining the toxicity of organic pollutants to animals and plants. In: Organic Pollutants: An Ecotoxicological Perspective, 2nd ed. CRC Press, London, pp. 17-66.

Wauchope, R.D., 1978. Pesticide content of surface-water draining from agricultural fields - Review. Journal of Environmental Quality 7, 459-472.

Zubrod, J.P., Bundschuh, M., Feckler, A., Englert, D., Schulz, R., 2011. Ecotoxicological impact of the fungicide tebuconazole on an aquatic decomposer-detritivore system. Environmental Toxicology and Chemistry 30, 2718-2724.

Zubrod, J.P., Bundschuh, M., Schulz, R., 2010. Effects of subchronic fungicide exposure on the energy processing of Gammarus fossarum (Crustacea; Amphipoda). Ecotoxicology and Environmental Safety 73, 1674-1680. 